\title{
Radiologic Variations of Nose and Paranasal Sinuses: A Ct Based Study
}

\author{
Authors \\ Priyanko Chakraborty ${ }^{1}$, Rajiv Kumar Jain ${ }^{2}$ \\ ${ }^{1}$ Resident, ${ }^{2}$ Professor And Head
}

Dept of Otorhinolaryngology, Institute of Medical Sciences, Banaras Hindu University, Varanasi-221005

Email: 'cpriyanko@gmail.com, 2jainrajivk@hotmail.com

\begin{abstract}
Background: Chronic rhinosinusitis (CRS) refers to a group of disorders characterized by inflammation of the mucosa of the paranasal sinuses. Computed tomography $(C T)$ scans used as the gold standard diagnostic modality of nose and paranasal sinus diseases. There has been a lot of studies regarding the anatomic variations leading to pathogenesis of paranasal sinus diseases. Considerable progress has been made in the medical and surgical control of these conditions; however, a large number of questions relating to the diagnosis, evaluation, and treatment of the diseases remain unanswered.

Material and Methods: The study included 82 clinically diagnosed cases of chronic rhinosinusitis who underwent CT scan were taken into the study. Supportive data was obtained from nasal endoscopy. The anatomical variations and pathological findings of the nose and paranasal sinuses were seen in the CT scan.

Results: The mean age $( \pm$ SEM) of presentation was 34.11 ( \pm 1.42$)$ years while most patients were from the age group of 18 to 30 years. Males were predominating the study group with $62.2 \%$ while $37.8 \%$ were females. Most common anatomic variation was DNS with $92.68 \%$ CT reported patients. This was followed by Inferior turbinate hypertrophy, septal spur, concha bullosa and agger nasi cells.

Conclusion: CT scan is considered gold standard for sinonasal imaging. Diagnostic endoscopy and CT scan is a must prior to any functional endoscopic sinus surgery. They help in assessing the extent of sinus disease and to know the variations and vital relations of the paranasal sinuses. CT scan assists the surgeon as a "road map" during ESS.
\end{abstract}

Keywords- Chronic rhinosinusitis; Nasal endoscopy; CT scan; Anatomic variation

\section{INTRODUCTION}

Chronic rhinosinusitis (CRS) is one of the common diseases affecting people globally with significant negative impact on quality of life. The term sinusitis refers to a group of disorders characterized by inflammation of the mucosa of the paranasal sinuses. Because the inflammation nearly always also involves the nose, it is now generally accepted that 'rhinosinusitis' is the preferred term to describe the inflammation of the nose and paranasal sinuses.
CT scan had been well accepted as a mandatory prerequisite for endoscopic sinus surgery, in suspected complications of sinusitis and in neoplasms of the nose and paranasal sinuses. In the diagnosis of CRS, its association with the symptoms score have been evaluated by a number of studies. However, due to the lack of agreement, high cost of CT scan and exposure to ionizing radiation, many do not recommended CT scan to form part of routine work up for CRS. Endoscopy often forms the first line 
investigation in chronic rhinosinusitis, but confirmation of the diagnosis is always by the CT scanning.

\section{MATERIALS AND METHODS}

The present study was conducted in Department of Otorhinolaryngology, Sir Sunderlal Hospital, Banaras Hindu University, Varanasi from ,January 2014 to July 2015. Sample size of 82 patients were included in the study with informed consent and clearance of ethical committee.

The patients were clinically diagnosed as a probable case of chronic rhinosinusitis on the basis of history and nasal endoscopy and then subjected to the investigative procedure viz. CT scan.

Thin slice coronal, axial and sagittal films were obtained both in soft tissue window and bone window for optimum visualization of all the structures. The investigations were done prior to initiation of any therapy. The selection of cases was based on a detailed clinical history of rhinosinusitis with duration of symptoms more than 12 weeks.

\section{Criteria for Selection of Cases: Inclusion criteria:}

- Patient attending outpatient department (OPD) or admitted patients who were clinically diagnosed as Chronic rhinosinusitis.

- Only those cases were registered, who gave full informed consent for the study.

- Adults of all age groups and both sexes were included.

\section{Exclusion criteria:}

- Patients with rhinosinusitis less than 12 weeks duration.

- Patients with allergic rhinitis.

- Patients with history of previous sinonasal surgeries.

- Patients with extensive nasal polyposis.

- Patients less than 18 years age.

Clinical diagnosis was based on subjective symptoms as defined by American Academy of Otolaryngology-Head and neck surgery (AAOHNS) task force criteria, which was revised in 2002 by the Sinus Allergy Health partnership (SAHP) task force. ${ }^{(1)(2)(3)}$

TABLE 1: Criteria for diagnosing chronic rhinosinusitis

\begin{tabular}{|l|l|}
\hline Major symptoms & Minor symptoms \\
\hline Nasal obstruction/blockage & Fever \\
\hline $\begin{array}{l}\text { Nasal discharge/purulence/discolored } \\
\text { postnasal discharge }\end{array}$ & Halitosis \\
\hline Hyposmia/anosmia & Headache \\
\hline Facial congestion/fullness & Cough \\
\hline $\begin{array}{l}\text { Facial pain/pressure (facial pain must } \\
\text { be accompanied by another major } \\
\text { factor to qualify for CRS). }\end{array}$ & Fatigue \\
\hline & Dental pain \\
\hline & $\begin{array}{l}\text { Ear pain/ear pressure } \\
\text { or fullness. }\end{array}$ \\
\hline $\begin{array}{l}\text { The guidelines define that the patient must have at least two } \\
\text { major factors or one major factor with two or more minor } \\
\text { factors, or nasal purulence on examination. Facial pain is not } \\
\text { considered to be a symptom of CRS without other nasal signs } \\
\text { and symptoms. The signs and symptoms should persist for at } \\
\text { least 12 weeks to qualify as a case of chronic rhinosinusitis. }\end{array}$ \\
\hline
\end{tabular}

The guidelines define that the patient must have at least two major factors or one major factor with two or more minor factors, or nasal purulence on examination. Facial pain is not considered to be a symptom of CRS without other nasal signs and symptoms. The signs and symptoms should persist for at least 12 weeks to qualify as a case of chronic rhinosinusitis.

\section{Clinical diagnostic criteria of CRS Revision (2002 SAHP Task Force) ${ }^{3}$ :}

1- Duration of disease is qualified by ongoing symptoms more than 12 weeks or more than 12 weeks of physical findings (signs will support the symptom time duration)

2- One of these signs of inflammation in association with symptoms:

a) Discoloured drainage, nasal polyp or polypoid swelling on physical examination with anterior rhinoscopy or nasal endoscopy

b) Edema or erythema of middle meatus as identified by nasal endoscopy

c) Generalized edema, erythema or granulation tissue (if it does not involve middle meatus or ethmoid bulla, radiological imaging is required. 
d) Imaging modalities for confirming the diagnosis: CT scan demonstrating mucosal thickening, bone changes or air fluid level. Plain

$\mathrm{X}$-ray with mucosal thickening of more than $5 \mathrm{~mm}$ or complete opacity.

(Plain X-ray without equivocal signs listed in A, B or $\mathrm{C}$ is not considered for diagnosis. MRI scan is not recommended for routine diagnosis because of lack of specificity. The endoscopy of frontal recess, middle meatus and sphenoethmoid recess were reviewed for presence of polyps, mucosal edema, congestion, discharge, scarring or crusting.)

All the assessments of endoscopy and CT were performed independently and assessors were blinded to each others' scores. The anatomical findings were assessed for every patient.

The data was tabulated and analyzed using the software program 'Statistical Product and Service Solutions' (SPSS) version 16.

\section{OBSERVATIONS AND RESULTS}

Only adults were included in the study. The mean age $( \pm$ SEM $)$ of presentation was $34.11( \pm 1.42)$ years while most patients were from the age group of 18 to 30 years. Males were predominating the study group with $62.2 \%$ while $37.8 \%$ were females. The table 2 depicts the anatomical findings seen in CT scan. 92.68\% patients had deviated nasal septum, $57.31 \%$ had inferior turbinate hypertrophy, $40.24 \%$ had septal spur, $30.48 \%$ had concha bullosa, agger nasi cell is found in $26.82 \%$.

Lesser number of patients had paradoxical middle turbinate $(14.63 \%)$, onodi cells were found in $10.97 \%$, haller cells in $9.7 \%$ and bent uncinate process only in $1.21 \%$.

Table 2 : CT scan findings (Anatomical variations)

\begin{tabular}{|l|l|l|}
\hline CT scan findings & $\begin{array}{l}\text { No. of } \\
\text { patient }\end{array}$ & Percentage \\
\hline DNS & 76 & $92.68 \%$ \\
\hline Septal Spur & 33 & $40.24 \%$ \\
\hline Inferior Turbinate Hypertrophy & 47 & $57.31 \%$ \\
\hline Concha Bullosa & 25 & $30.48 \%$ \\
\hline Onodi Cells & 9 & $10.97 \%$ \\
\hline Haller Cells & 8 & $9.7 \%$ \\
\hline Agger Nasi Cells & 22 & $26.82 \%$ \\
\hline Bent Uncinate Process & 1 & $1.21 \%$ \\
\hline Paradoxical Middle Turbinate & 12 & $14.63 \%$ \\
\hline
\end{tabular}

The following table 3 shows the frequency of pathological findings in CT scan. Sinus haziness and ostiomeatal complex involvement are the most important factors which are to be studied in CT scan of paranal sinuses.

Table 3 CT scan findings (Pathological findings)

\begin{tabular}{|l|l|l|}
\hline CT Scan Findings & $\begin{array}{l}\text { No. of } \\
\text { patient }\end{array}$ & Percentage \\
\hline Polyp in Middle Meatus & 9 & $10.97 \%$ \\
\hline Maxillary Sinus opacification & 58 & $70.73 \%$ \\
\hline Ethmoidal Sinus opacification & 48 & $58.53 \%$ \\
\hline Sphenoidal Sinus opacification & 30 & $36.58 \%$ \\
\hline Frontal Sinus opacification & 22 & $26.82 \%$ \\
\hline Blocked Hiatus Semilunaris & 28 & $34.14 \%$ \\
\hline Frontal Recess Block & 10 & $12.19 \%$ \\
\hline Sphenoethmoid Recess Block & 17 & $20.73 \%$ \\
\hline
\end{tabular}

Frequency of involvement of sinuses is shown in table 4. Most patients had multiple sinus involveement (48.78\%). Pansinusitis was found in $12.19 \%$. Isolated sinus involvement is not much common. Maxillary sinus was involved alone in $21.9 \%$, isolated etmoidal in $1.21 \%$, isolated sphenoidal in $6.09 \%$ and isolated frontal in $2.43 \%$. $7.3 \%$ patients had no sinus involvement.

Table 4 : Involvement of Sinuses in CT

\begin{tabular}{|l|l|l|}
\hline CT scan findings & $\begin{array}{l}\text { No. of } \\
\text { patient }\end{array}$ & Percentage \\
\hline Maxillary Sinus & 58 & $70.73 \%$ \\
\hline Ethmoidal Sinus & 48 & $58.53 \%$ \\
\hline Sphenoidal Sinus & 30 & $36.58 \%$ \\
\hline Frontal Sinus & 22 & $26.82 \%$ \\
\hline Isolated Maxillary & 18 & $21.9 \%$ \\
\hline Isolated Ethmoidal & 1 & $1.21 \%$ \\
\hline Isolated Sphenoidal & 5 & $6.09 \%$ \\
\hline Isolated Frontal & 2 & $2.43 \%$ \\
\hline Pansinusitis & 10 & $12.1 \%$ \\
\hline Involvement of Multiple Sinuses & 40 & $48.78 \%$ \\
\hline None of The Sinuses Involved & 6 & $7.3 \%$ \\
\hline
\end{tabular}

All the cases in our study were clinically diagnosed as a case of chronic rhinosinusitis. However after CT scan and endoscopy the final diagnosis showed. $92.68 \%$ were actually cases of chronic rhinosinusitis. 3 cases were of deviated nasal septum, 1 case each of atrophic rhinitis, carcinoma maxilla and rhinitis. 


\section{DISCUSSION}

Chronic rhinosinusitis remains one of the most common diseases with negative impact on quality of life. It has a high prevalence rate of about $10.9 \%$ as found out in an European study the GA2LEN study. ${ }^{4}$ CT scan is considered as the gold standard in diagnosing rhinosinusitis while nasal endoscopy is performed to look for anatomic variations and mucosal changes. It has been recommended that either a CT scan or endoscopic evaluation of nose (preferably with photo or video documentation) should be a part of any prospective clinical trial, as it provides the majority of objective data used to diagnose CRS. ${ }^{5-9}$

The pneumatization of the middle turbinate (concha bullosa) may block the entrance to the middle meatus by creating area of mucosal contact. ${ }^{12}$ It has been implicated as possible etiology factor in recurrent sinusitis due to its postulated negative influence on paranasal sinus ventilation. ${ }^{13}$ Presence of concha bullosa is also a variable finding reported by Kennedy et al (1988) in 36\%, Lloyd (1990) in $14 \%$ and Lloyd et al in (1991) in $24 \%$ patients, Zinreich et al (1989) in 36\%, Asruddin et al(2001) in $28 \%$.

In our study the prevalence of DNS was found to be staggeringly high at $92.68 \%$ which was way above the findings of other studies. A study done in Indian population found out DNS in $65 \%$ of patients with headache or nasal symptoms. ${ }^{22}$ Another study found out prevalence of DNS to be $80 \%$ which was closer to our result than others. ${ }^{10}$

As demonstrated in the table 5, In our study concha bullosa was seen on CT examination in 25 (30.48\%) cases. Which is comparable to studies of Zinreich et al, Shroff et al (1996) and Wani et al (2006).

Controversially, in another study it was said that DNS and Concha bullosa are said not to have any significant correlation in pathogenesis of CRS. ${ }^{11}$ But we found high prevalence of DNS amongst our patients (92.68\% reported in CT scan).

Paradoxical middle turbinate may block the entrance to the middle meatus. ${ }^{12}$ It is a very variable feature, Lloyd (1990) reported it in $17 \%$ of cases, $12 \%$ by Asruddin et al (2001), $15 \%$ by Zinreich et and Shroff et al 16\% and Bolger et al 6.1\%. In our study as demonstrated in table, on CT scan paradoxical bent middle turbinate was found in $14.63 \%$ cases which is comparable to Zinreich et al 1987, Lloyd et al (1990), Shroff et al 1996 and Asruddin et al 2001.

Haller cells protrude from the floor of orbit. These are known to cause narrowing of the maxillary ostium. We found the presence of Haller cells in $9.7 \%$. Lloyd reported frequency of Haller cells as $2 \%$ and $15 \%$ cases in two separate studies done in 1990 and $1991 .^{14,15}$ Thus there is a wide variation in Haller cell frequency. Our findings were closer to Zinreich et al findings who found haller cells cells in $10 \%$ of cases

Agger nasi cells on the lateral wall represent the most anterior of the anterior extra ethmoid air cells. $^{21}$ Agger nasi cells are sid to obstruct the frontal recess thereby obstructing frontal.

sinus drainage. In our study, agger nasi were present in $26.82 \%$ patients. The presence of agger nasi cells is a variable finding. As Lloyd (1990) reported its presence in $3 \%$ cases while Maru et al found in $88.5 \%$ casesThe uncinate process may be bent in two difference directions. Its posterior margin may be deflected medially so that is approximates to the middle turbinate; or it may be laterally narrowing the hiatus semilunaris and the ethmoid infundibulum (Lloyd 1990). ${ }^{14}$ In our study on the CT plate examination, the bent uncinate process was present in 1 case of 82 cases. It is a variable finding. (Lloyd 1990) reported its presence in $16 \%$ cases and the same author reported in another study done in 1991 its presence in $21 \%$ cases. Our result is comparable to the study of Asruddin et al (2001) who obtained $2 \%$.

There are significant number of various parameters that cannot be visualized at nasal endoscopy viz middle meatus, bulla ethmoidalis, hiatus semilunaris and frontal recess. This is because in some cases it is impossible to pass the endoscope beyond certain point due to severe anatomical abnormalities like a severely deviated nasal septum, paradoxical middle turbinate, or a concha bullosa. CT scan definitely prove to be very helpful in these cases. 
For proper evaluation of ethmoid sinuses, CT is mandatory because inflammatory changes in the middle meatus and ethmoids are poorly seen on plain radiographs. In this setting CT can establish the extent of disease, help the clinician determine if full patency of the narrow passage has been reestablished after surgery. For functional endoscopic sinus surgery, CT is a prerequisite to know the "road map" for surgery (Zinreich et al 1987). ${ }^{13}$

\begin{tabular}{|c|c|c|c|c|c|c|c|c|c|}
\hline Anatomic variants & $\begin{array}{l}\text { Zinreich } \\
\text { et al }{ }^{13}\end{array}$ & $\begin{array}{l}\text { Lloyd } \\
\text { et } \mathrm{al}^{14}\end{array}$ & $\begin{array}{l}\text { Lloyd et } \\
\text { al }^{15}\end{array}$ & $\begin{array}{l}\text { Bolger } \\
\text { et al }{ }^{17}\end{array}$ & $\begin{array}{l}\text { Shroff } \\
\text { et al }\end{array}$ & $\begin{array}{l}\text { Asruddi } \\
\text { n et al }\end{array}$ & $\begin{array}{l}\text { Maru } \\
\text { et al }{ }^{19}\end{array}$ & $\begin{array}{l}\text { Wani } \\
\text { et } \mathbf{a l}^{20}\end{array}$ & $\begin{array}{l}\text { Present } \\
\text { study }\end{array}$ \\
\hline Concha bullosa & $36 \%$ & $14 \%$ & $24 \%$ & $51 \%$ & $33 \%$ & $28 \%$ & $42.6 \%$ & $30 \%$ & $30.48 \%$ \\
\hline DNS & $21 \%$ & - & - & $40 \%$ & $33 \%$ & $38 \%$ & $55.7 \%$ & $25.3 \%$ & $92.68 \%$ \\
\hline Paradoxical middle turbinate & $15 \%$ & $17 \%$ & $15 \%$ & $6.1 \%$ & $16 \%$ & $12 \%$ & $9.8 \%$ & $9.33 \%$ & $14.63 \%$ \\
\hline Haller cell & $10 \%$ & $2 \%$ & $15 \%$ & $5.1 \%$ & $6 \%$ & $28 \%$ & $36.1 \%$ & $8.66 \%$ & $9.7 \%$ \\
\hline Enlarge ethmoid bulla & $8 \%$ & $17 \%$ & $18 \%$ & - & $8 \%$ & $9 \%$ & - & - & - \\
\hline Bent Uncinate process & $3 \%$ & $16 \%$ & $21 \%$ & $2.5 \%$ & $3 \%$ & $2 \%$ & $9.8 \%$ & $11 \%$ & $1.21 \%$ \\
\hline Agger nasi cell & - & $3 \%$ & $14 \%$ & - & $9.8 \%$ & $48 \%$ & $88.5 \%$ & $9.33 \%$ & $26.82 \%$ \\
\hline Maxillary antrum septae & - & - & - & - & - & $18 \%$ & $6.6 \%$ & - & - \\
\hline
\end{tabular}

\section{CONCLUSION}

Advantages of CT scan:

- It shows progressive deeper structures as the surgeon encounters them during operation (eg: uncinate process, bulla ethmoidalis, ground lamella, sphenoid sinus, in an A-P direction).

- It shows the relationships of the above structures to important areas such as the lamina papyracea and skull bone, reducing the morbidity.

- Dehiscence of the lamina papyracea are better visualized.

- Comparative study of two sides of the ethmoids labyrinth is possible.

To sum up, the CT scan serves as a "road map" for the surgeon as he negotiates the potentially hazardous clefts of the PNS unit. It is a non invasive, rapid, convenient investigation, which helps in documentation and education. As already mentioned CT scan delineates the extent of disease, anatomical and pathological variations far better than other methods.

\section{Disadvantages of CT scan:}

- Radiation dose to the sensitive areas like cornea and lens is particularly high when axial cuts are taken nearly 185 times more than that recorded for plain X-rays. Careful positioning of the patient in the scanner can reduce this.

- Inability to differentiate between fibrous tissue (post-op) and inflammatory mucosal disease. Thus CT scan falsely indicates recurrent disease because of the presence of post operative fibrosis in the paranasal sinuses (i.e. specificity of CT is lower than the sensitivity of CT)

- Relatively expensive investigation.

CT scan should be used to provide supplementary clinical data to the history and endoscopic examination, and assist in directing surgical treatment to the affected areas.

\section{REFERENCES}

1. Slavin RG et al., American Academy of Allergy, Asthma and Immunology; American College of Allergy, Asthma and Immunology; Joint Council of Allergy, Asthma and Immunology: The diagnosis and management of sinusitis: a practice parameter update. J Allergy Clin Immunol 2005, 116(6 Suppl):S13-S47.

2. Rosenfeld RM: Clinical practice guideline on adult sinusitis. Otolaryngol Head Neck Surg 2007, 137(3):365-377

3. Benninger MS, Ferguson BJ, Hadley JA, Hamilos DL, Jacobs M, Kennedy DW, et al. 
Adult chronic rhinosinusitis: definitions, diagnosis, epidemiology, and pathophysiology. Otolaryngol Head Neck Surg 2003 Sep;129(3) (Suppl):S1-S32.

4. Hastan D, Fokkens WJ,et al: Chronic rhinosinusitis in Europe - an underestimated disease. A GA(2) LEN study. Allergy 2011, 66(9):1216-1223.

5. Zinreich SJ. Rhinosinusitis: radiologic diagnosis. Otolaryngol Head Neck Surg.1997;117(part 2):27-34.

6. Lund VJ, Kennedy DW. Staging for rhinosinusitis. Otolaryngol Head Neck Surg. 1997;117(part 2):35- 40.

7. Stewart MG, Sicard MW, Piccirillo JF, Diaz-Marchan PJ. Severity staging in chronic sinusitis: are CT scan findings related to patient symptoms? Am J Rhinol. 1999;13:161-167.

8. Bhattacharyya T, Piccirillo J, Wippold J. Relationship between patient-based descryption of sinusitis and paranasal sinus computed tomographic findings. Arch Otolaryngol Head Neck Surg. 1997;123:1189-92.

9. Rosbe KW, Jones KR. Usefulness of patient symptoms and nasal endoscopy in the diagnosis of chronic rhinosinusitis. Am J Rhinol. 1998;12:167-171

10. Pinas IP, Sabate J, Carmona A, Herrera CJ and Castellanos J(2000) Anatomical variations in the human paranasal sinus region studied by CT. J. Anat.197, 221-227.

11. Vincent TE, Gendeh BS. The association of concha bullosa and deviated nasal septum with chronic rhinosinusitis in functional endoscopic sinus surgery patients.Med J Malaysia. 2010;65(2):108-11.

12. Stamberger H, Wolf G. Headache and sinus disease the endoscopic approach. Ann Otol Rhinol Laryngol 1988; 34: 2-23.

13. Zinreich SJ, Kennedy DW, Rosenbaum AE, Gayler BW, Kumar AJ, Stammberger H: Paranasal sinuses: CT imaging requirements for endoscopic surgery. Radiology 1987, 163(3):769-775.

14. Lloyd GA. CT of the paranasal sinuses: study of a coronal series in relation to endoscopic sinus surgery. J Laryngol Otol 1990 Jun; 104 (6): 477-81.

15. Lloyd et al. CT of paranasal sinuses and Functional endoscopic sinus Surgery: A critical analysis of 100 symptomatic patients. J Laryngol Otol 1991; 105: 181-5.

16. Asruddin, Yadav SPS, Yadav RK, Singh J. Low dose CT in chronic sinusitis. Indian Journal of Otolaryngology and Head Neck Surgery 2000; 52: 17-21.

17. Bolger et al. PNS Surgery : Anatomic variations and mucosal abnormalities: CT analysis for endoscopic sinus surgery. Laryngoscope 1991; 101: 56-64.

18. Shroff MM, Shetty PG, Kirstane MV. Coronal screening sinus CT in inflammatory sino-nasal disease. Indian Journal of Radiology and Imaging 1996; 6: 3-17.

19. Maru YK, Gupta Y. Concha Bullosa: Frequency and appearance on Sinonasal on Sinonasal CT. Indian Journal of Otolaryngology and Head \&Neck Surgery 2000; 1:40-4.

20. Wani AA, Kanotra S, Lateef M, Ahmad R, Qazi SM, Ahmad S. CT scan evaluation of the anatomical variations of the ostiomeatal complex. Indian j Otolaryngol Head Neck Surg 2009 july-Sept; 61(3):163-8

21. Mafee MF. Preoperative imaging anatomy of nasal-ethmoid complex for functional endoscopic sinus surgery. Radiology Clinics of North America 1993; 31: 1-19.

22. Mamatha H, Shamasundar NM, Bharathi M, Prasanna L. Variations of ostiomeatal complex and its applied anatomy: a CT scan study. Indian J Sci Technol 2010; 3: 904-7. 